\title{
Mortality Attributed to Myocardial Infarction in the Male and Female Population of Salvador, BA, between 1981 and 1996
}

\author{
Luiz Carlos Santana Passos, Antonio Alberto Lopes, Ines Lessa, Adelina Sanches, Rogério Santos-Jesus
}

\author{
Salvador, BA - Brazil
}

\begin{abstract}
Objective - To describe according to gender the trend in mortality attributed to myocardial infarction (MI) in the population of Salvador, Bahia between 1981 and 1996.

Methods - This study was on mortality due to MI estimates by period and gender of the city of Salvador, Bahia. Data from 1981 to 1996 were stratified by quadrienia, and the percentage reduction in death rate due to $M I$ relative to the preceding period (PRR) was determined. Comparisons between genders were expressed by the male/female death ratio $(D R)$ based on the gender-related PPR.
\end{abstract}

Results - An overall increase of approximately $8 \%$ was observed in the death rate attributed to MIfor the period 1985-1988 (89.2/10 5 individuals / year) versus the period 1981-1984 (82.1/105/ year). In the subsequent periods, overall reductions of $10 \%$ and $20.3 \%$ were observed for the periods 1989-1992 and 1993-1996, respectively. For men, the PPRs were 11.1 in the period 1989-1992 and 22.7\% in the period 1993-1996. The PPRs in women were lower: $8.6 \%$ and $17.4 \%$ between 1989 and 1992, and 1993 and 1996, respectively. Death rate reduction was greater for men than women, then the malel female DR decreased from 1.66 in 1981-1984 to 1.35 in 1993-1996.

Conclusion - The results indicate a trend towards a reduction in the death rate attributed to myocardial infarction in the city of Salvador from the second half of the 1980s onwards, striking in men.

Keywords: trend, mortality, myocardial infarction, gender

Faculdade de Medicina e Instituto de Saúde Coletiva da Universidade Federal da Bahia

Mailing address: Luiz Carlos Santana Passos - Rua Amir Macedo, 119/1003 40285-460, Salvador, BA - Brazil
Studies performed outside of Brazil have shown a persistent decline in mortality attributed to coronary artery disease over the last three decades ${ }^{1-4}$. This phenomenon may, in part, be due to the reduction in the incidence of coronary artery disease believed to be related to behavior modifications (e.g., diet, smoking, physical activity) and to better control of hypertension. Another contributing factor lies in the increased survival of these patients, leading to a greater probability of death due to other causes.

Evidence exists that during the last few decades the introduction of new diagnostic and therapeutic resources has also contributed to a better prognosis for patients with coronary artery disease. It is important, however, to consider that sociodemographic factors are associated with the utilization of such new diagnostic and therapeutic advances. Recent studies demonstrate that men with acute myocardial infarction undergo more frequent and more precocious interventions compared with women ${ }^{5-7}$. It is therefore plausible that gender is related to different patterns in the temporal tendency towards mortality attributed to acute myocardial infarction.

Despite the availability of pertinent specific information, analyses of the evolution of mortality due to coronary artery disease are still scanty in Brazil. Lolio et al ${ }^{8}$ suggest that in Salvador mortality due to ischemic heart disease remained stable between 1979 and 1989 in men and in women aged 35 to 64 years. Yet, these authors did not evaluate the specific evolution of mortality attributed to acute myocardial infarction. Furthermore, the 10-year period of this evaluation preceded the use of thrombolytic therapy and primary angioplasty, which have become ever more commonly used since then. The present study aims to describe the evolution of mortality due to acute myocardial infarction in both genders in the city of Salvador, BA, between 1989 and 1996.

\section{Methods}

Data relative to the annual frequency of deaths attributed to acute myocardial infarction (CID 410) in the city of Salvador between 1981 and 1996 were obtained via the 
DATA SUS System of the Ministry of Health and supplemented by technical reports from the Health Information Center (CIS) of the Department of Health of the State of Bahia (SESAB) relative to the years 1994-1996 ${ }^{9}$. Only data referring to death of individuals over 30 years of age were considered. Deaths attributed to acute myocardial infarction were 4,265 for male and 3,530 for female individuals. Population data for individuals over 30 years of age obtained from statistical annals from IBGE ${ }^{10}$ for the city of Salvador were used for calculations of gender coefficients.

Four periods (1981-1984, 1985-1988, 1989-1992 and 1993-1996) were selected for analysis. For each period from 1985-1988 on, the percent reduction relative to total and gender-specific acute myocardial infarction mortality in the preceding period was determined. Comparisons between the decline in mortality by gender for each period are expressed by death ratios (DR).

\section{Results}

Increased mortality due to acute myocardial infarction was observed in the period between 1985 and 1988 in relation to the period between 1981-1984 (89.2/105 individuals/ years vs $82.1 / 10^{5}$ individuals/ years, respectively). This initial tendency towards increased mortality was not observed in the following periods. The reduction was $10 \%$ for $1989-$ 1992 (relative to $1985-1988$ ) and of $20.3 \%$ for $1993-1996$ (relative to 1989-1992) (table I).

Table II presents mortality data attributed to acute myocardial infarction per 100,000 inhabitants according to gender over 4 year periods. Although the tendency toward a decline in mortality attributed to acute myocardial infarction over the years occurs in both sexes, the percent reduction was greater in males then females (fig. 1). As a result, the death ratio (males vs females) is gradually falling, indicating

\begin{tabular}{|lllll|}
\hline \multicolumn{5}{|c|}{ Table I - Mortality attributed to acute myocardial infarction, } \\
according to time.
\end{tabular}

that mortality in men is showing a tendency toward declining to the level of that occurring in women.

\section{Discussion}

Our findings indicate that a gradual reduction in mortality attributed to acute myocardial infarction has been occurring since the second half of the 1980s. This tendency could possibly be part of the same phenomenon observed since the 1970s in European and North American countries.

The data obtained also indicate that the decline in mortality atributted to acute myocardial infaction is more pronounced in men than in women. Although the present analysis was conducted over a relatively short period, our findings agree with those of Gillium ${ }^{4}$. By analyzing population data from the Centers for Disease Control and Prevention, National Center for Health Statistics of the United States, Gillium showed that over the last decade the reduction in mortality due to ischemic heart disease was greater in men than in women.

The possible reasons for this difference have not been directly examined in the present study. One potential explanation may be the differences between men and women relative to the control of coronary risk factors over time. Another possible explanation is the lower use of diagnostic and thera-peutic interventions in women with established coronary atherosclerosis a finding observed in other studies $^{5,7,12,13}$.

The less favorable prognosis for women with acute myocardial infarction has been described in recent studies ${ }^{14,15}$. Similar findings were observed in hospitals in the city of Salvador ${ }^{16,17}$. Different patterns of temporal tendencies in the

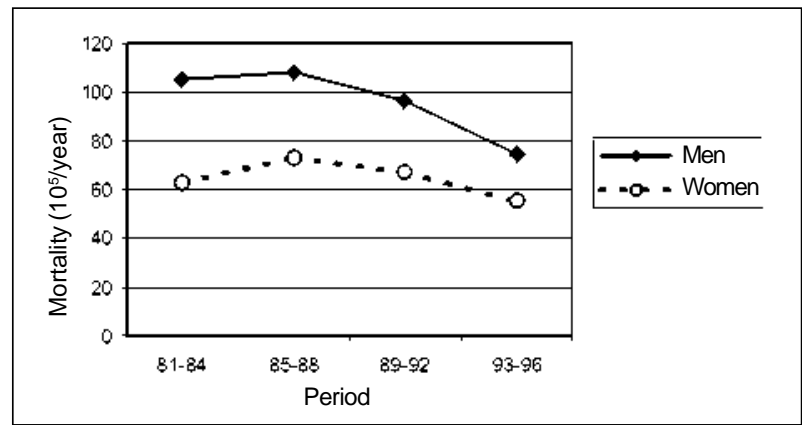

Fig. 1 - Mortality per 100,000 inhabitants, attributed to acute myocardial infarct according to time period (1981-1996) and sex.

\begin{tabular}{|c|c|c|c|c|c|c|c|c|}
\hline Period & Deaths & $\begin{array}{l}\text { Masculine } \\
\text { Population }\end{array}$ & Mortality & PPR & Deaths & $\begin{array}{c}\text { Feminine } \\
\text { Population }\end{array}$ & Mortality & DR \\
\hline $81-84$ & 938 & 892.527 & 105.095 & - & 681 & 1.078 .169 & 63.163 & - \\
\hline $85-88$ & 1.099 & 1.013 .915 & 108.392 & no reduction & 898 & 1.224 .804 & 73.318 & no reduction \\
\hline $89-92$ & 1.173 & 1.216 .681 & 96.409 & $11.1 \%$ & 992 & 1.480 .938 & 66.985 & $8.6 \%$ \\
\hline $93-96$ & 1.055 & 1.415 .666 & 74.523 & $22.7 \%$ & 959 & 1.734 .063 & 55.304 & $17.4 \%$ \\
\hline
\end{tabular}


acute myocardial infarction mortality in both sexes can also be explained by a more marked reduction in death due to this condition in men versus women. This possibility is based on evidence that new forms of diagnostic and therapeutic interventions have been utilized to a greater extent in men compared with women ${ }^{5,7,12,13}$. It is important to note that the prognosis of acute myocardial infarction in women is worse than in men.
In conclusion, this study demonstrates a tendency towards reduction in mortality attributed to acute myocardial infarction in the city of Salvador from the second half of the 1980s onward. This reduction has been more pronounced in men than in women, rendering greater mortality in men ever closer to the lower mortality in women. The reasons for the differing temporal tendencies between the sexes are not clear, and so they remain an important subject for future investigations.

\section{References}

1. Higgins MW, Luepker RV. Trends and determinants of coronary heart disease mortality: International comparisons. Int J Epidemiol 1989;18(suppl 1): S1-S2.

2. Sytkowsky PA, Kannel WB, D' Agostino RB. Changes in risk factors and the decline in mortality from cardiovascular disease: The Framingham Study. NEngl J Med 1990; 322: 1635-41.

3. D' Agostino RB, Kannel WB, Belanger AJ, Sytkowsky PA. Trends in CHD and risks factors at age 55-64 in the Framingham Study. Int J Epidemiol 1989; 18(suppl 1): 567-72.

4. Gillum RF. Tends in acute myocardial infarction and coronary heart disease death in the United States. J Am Coll Cardiol 1994; 23: 1273-7.

5. Kostis JB, Wilson A, O'Dowd K and Midas Study Group. Sex differences in the management and long-term outcome of acute myocardial infarction. Circulation 1994, 90: 1715-32.

6. Herholz H, Goff DC, Ramsey DJ, et al. Women and Mexican Americans receive fewer cardiovascular drugs following myocardial infarction than men and nonhispanic whites: the corpus christi heart project, 1988-1990. J Clin Epidemiol 1996; 49: 279-87.

7. Clarke W, Gray D, Keating NA, Hamptom JR. Do women with acute myocardial infartion receive the same treatment as men? Br Med J 1994; 309: 563.

8. Lólio CA, Lotufo PA, Lira AC,Zaneta DMT, Massad E. Tendência da mortalidade por doença isquêmica do coração nas capitais de regiões metropolitanas do Brasil, 1979-1989.
9. Brasil. Ministério da Saúde. Sistema de Informações sobre Mortalidade (19791993). Fundação Nacional de Saúde.

10. Fundação IBGE-IX Censo demográfico 1980, Rio de Janeiro, 1983.

11. Fundação IBGE-X Censo demográfico 1991, Rio de Janeiro, 1993.

12. Maynard C, Althouse R, Cerqueira M, Olsufka, Kennedy JW. Underutilization of thrombolytic therapy in eligible women with acute myocardial infarction. Am J Cardiol 1991; 68: 529-30.

13. Roger L, Jacobsen SJ, Pellikka AP, Millier TD, Baley KR, Gersh BJ. Gender differences in use of stress testing and coronary heart disease mortality - A population based study in Olmsted County, Minnesota. J Am Coll Cardiol 1998; 2: 345-52.

14. Vaccarino V, KrumholzHM, Berkman LF, HorwitzRI. Sex differences in mortality after myocardial infarction. Circulation 1995; 91: 1861-71.

15. Malacrida R, Genone M, Maggioni AP, et al. A comparison of the early outcome of acute myocardial infarction in women and men. N Engl J Med 1998; 338: 8-14.

16. Passos LCS, Lopes AA, Barbosa AA, Santos-Jesus R. Por que a letalidade hospitalar do infarto agudo do miocárdio é maior entre as mulheres? Arq Bras Cardiol 1998, 70; 327-30.

17. Lessa I, Cortes EQ, Souza JA, Souza Filho J, Pondé Netto J, Almeida FA. Epidemiology of acute myocardial infarction in Salvador, Brazil. Incidence, lethality, and mortality. PAHO Bull 1987; 21: 28-37. 